Supplement of Geosci. Model Dev., 11, 1421-1442, 2018

https://doi.org/10.5194/gmd-11-1421-2018-supplement

C Author(s) 2018. This work is distributed under

the Creative Commons Attribution 4.0 License.

(c) (1)

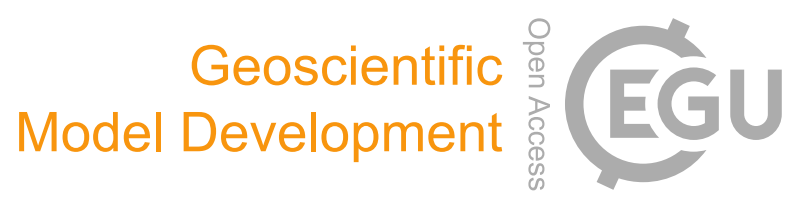

Supplement of

\title{
A protocol for the intercomparison of marine fishery and ecosystem mod- els: Fish-MIP v1.0
}

Derek P. Tittensor et al.

Correspondence to: Derek P. Tittensor (derek.tittensor@unep-wcmc.org)

The copyright of individual parts of the supplement might differ from the CC BY 4.0 License. 
GFDL mean temperature 1990-1999

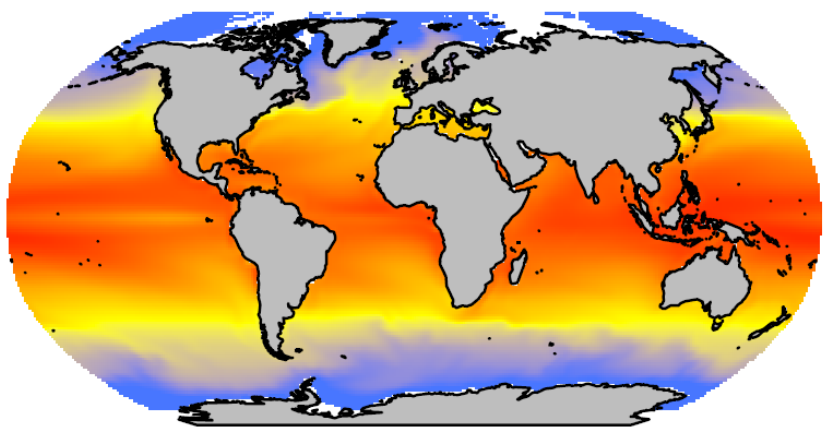

GFDL RCP 2.6 mean change 2090-2099

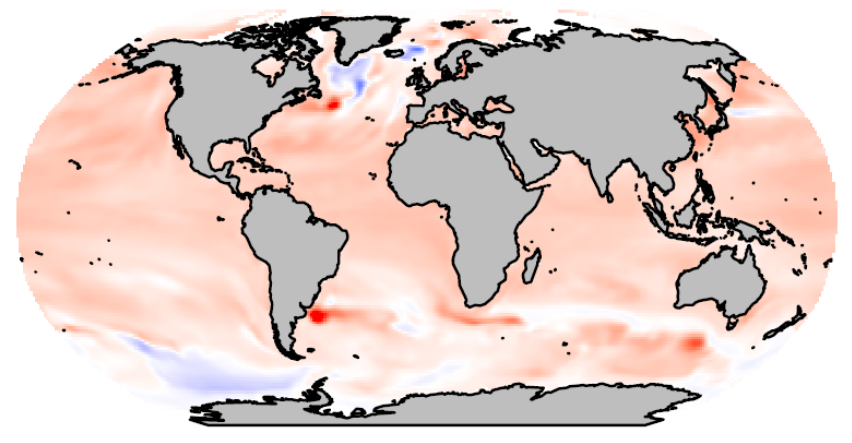

GFDL RCP 8.5 mean change 2090-2099

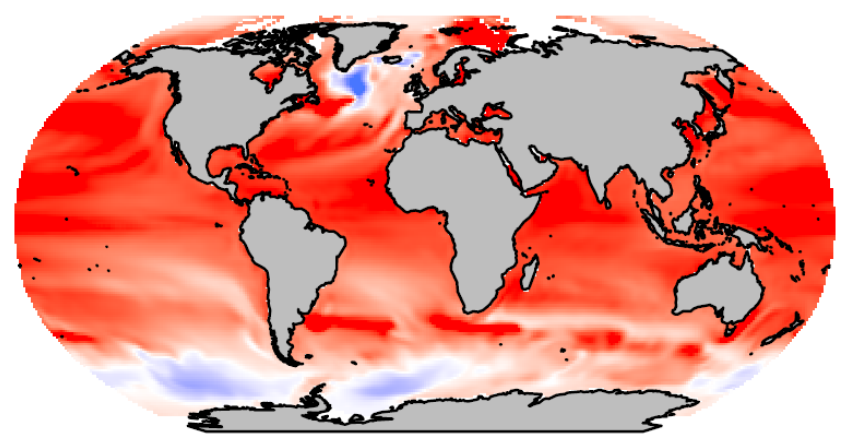

IPSL mean temperature 1990-1999
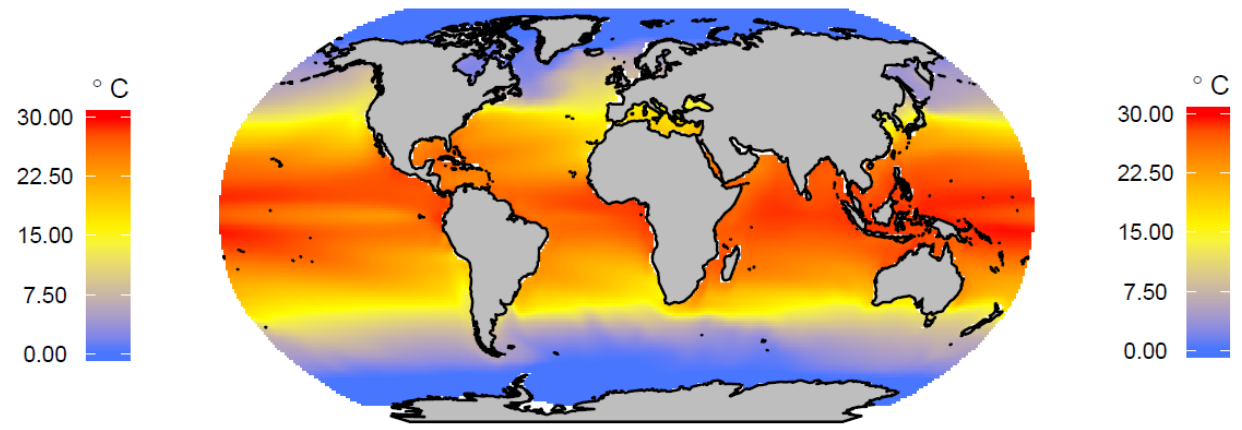

IPSL RCP 2.6 mean change 2090-2099
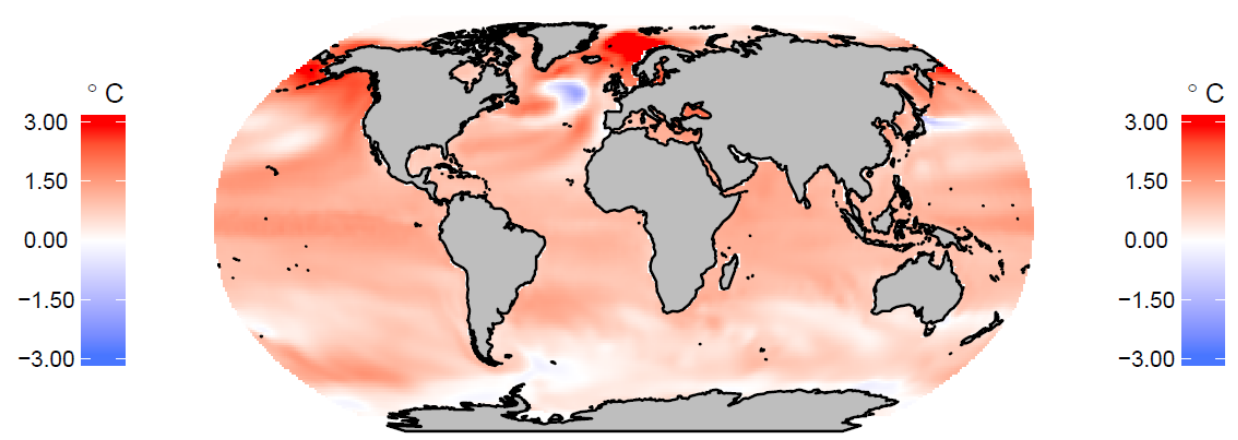

IPSL RCP 8.5 mean change 2090-2099
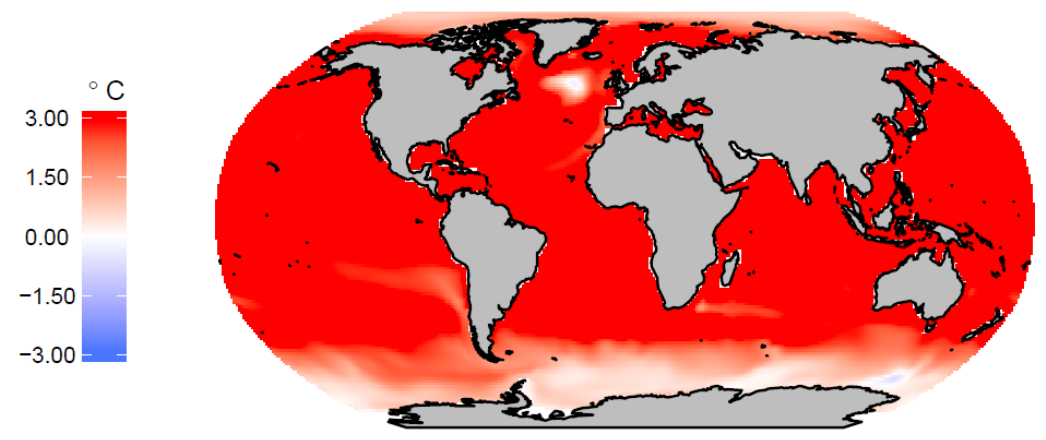
Figure S1: Example model forcings for the models participating in Fish-MIP. Figure shows mean annual sea-surface temperature (SST) from GFDL-ESM2M and IPSL-CM5A-LR for the period 1990-1999 (historical run) and the mean annual absolute change for 2090-2099 under the IPCC AR5 RCP 2.6 and RCP 8.5 scenarios. Note that some Fish-MIP models used partial or full water column three-dimensional data. All ESM forcing data were provided by ISI-MIP as described in the main manuscript. 
GFDL mean NPP 1990-1999

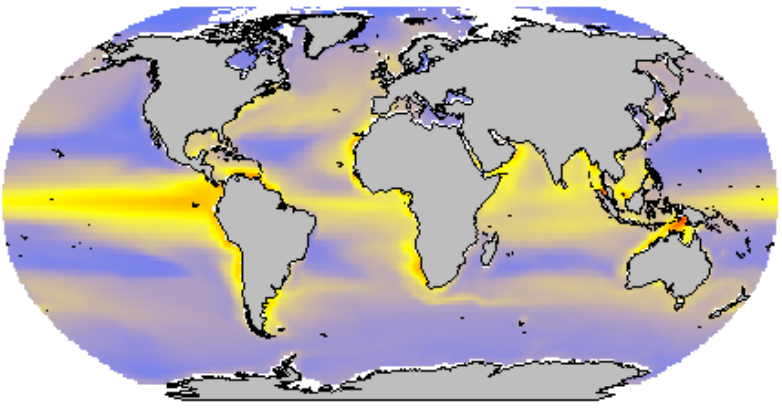

GFDL RCP 2.6 mean change 2090-2099

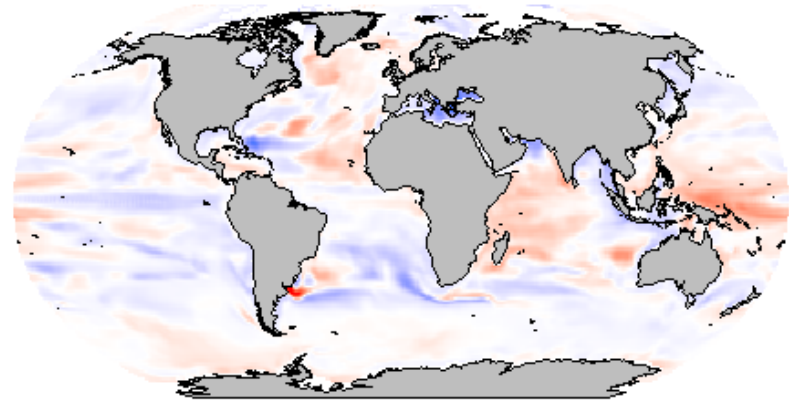

GFDL RCP 8.5 mean change 2090-2099

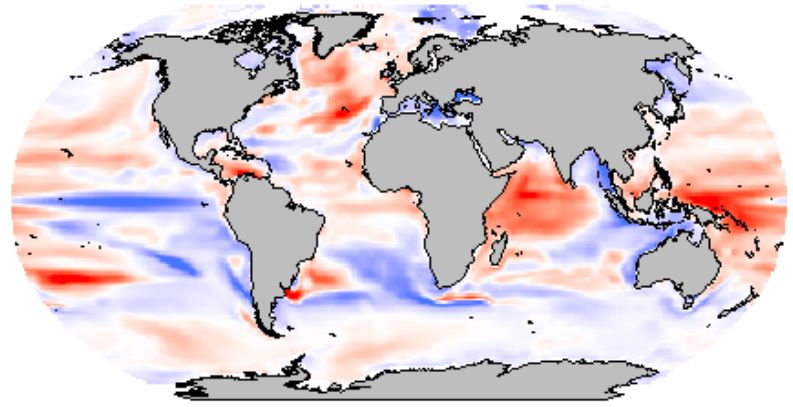

IPSL mean NPP 1990-1999
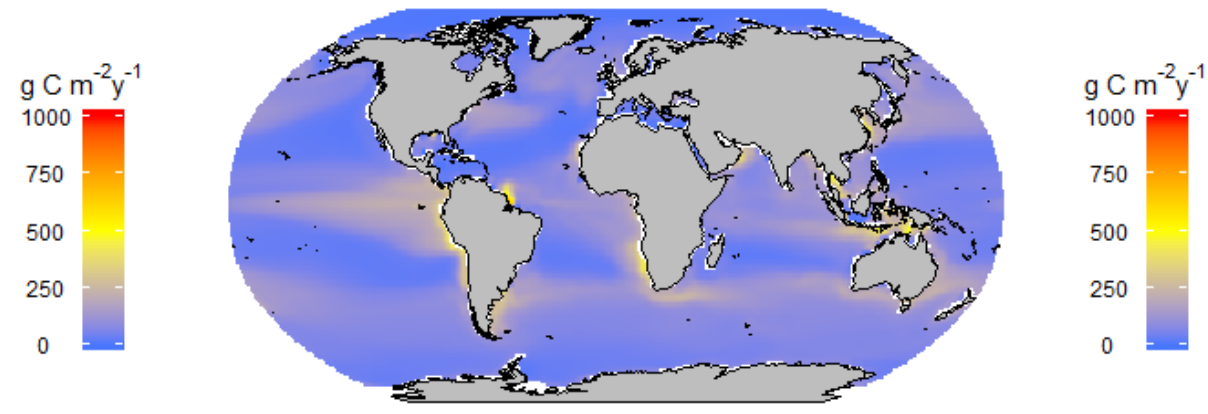

IPSL RCP 2.6 mean change 2090-2099
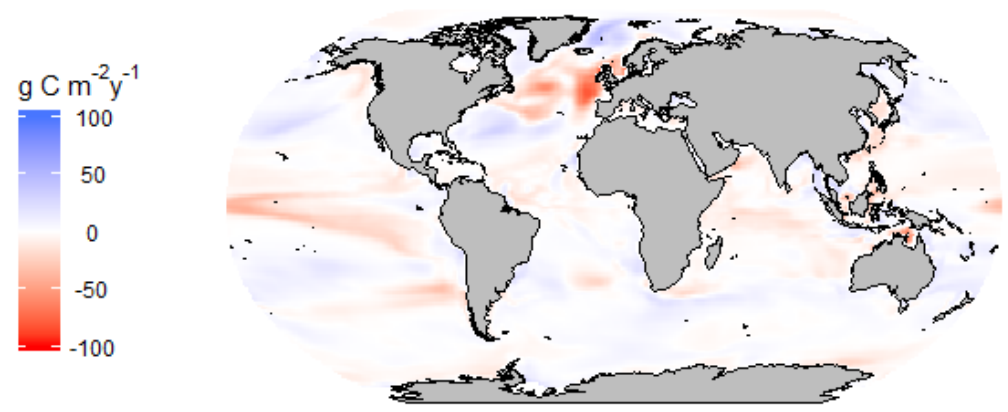

$\mathrm{g} \mathrm{C} \mathrm{m} \mathrm{m}^{-2}$

100

50

0

$-50$

IPSL RCP 8.5 mean change 2090-2099

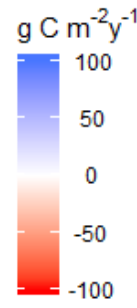


Figure S2: Example model forcings for the models participating in Fish-MIP. Figure shows mean annual depth-integrated net primary productivity from GFDL-ESM2M and IPSL-CM5A-LR for the period 1990-1999 (historical run) and the mean annual absolute change for 2090-2099 under the IPCC AR5 RCP 2.6 and RCP 8.5 scenarios. Note that some Fish-MIP models used partial or full water column three-dimensional data. All ESM forcing data were provided by ISI-MIP as described in the main manuscript. 


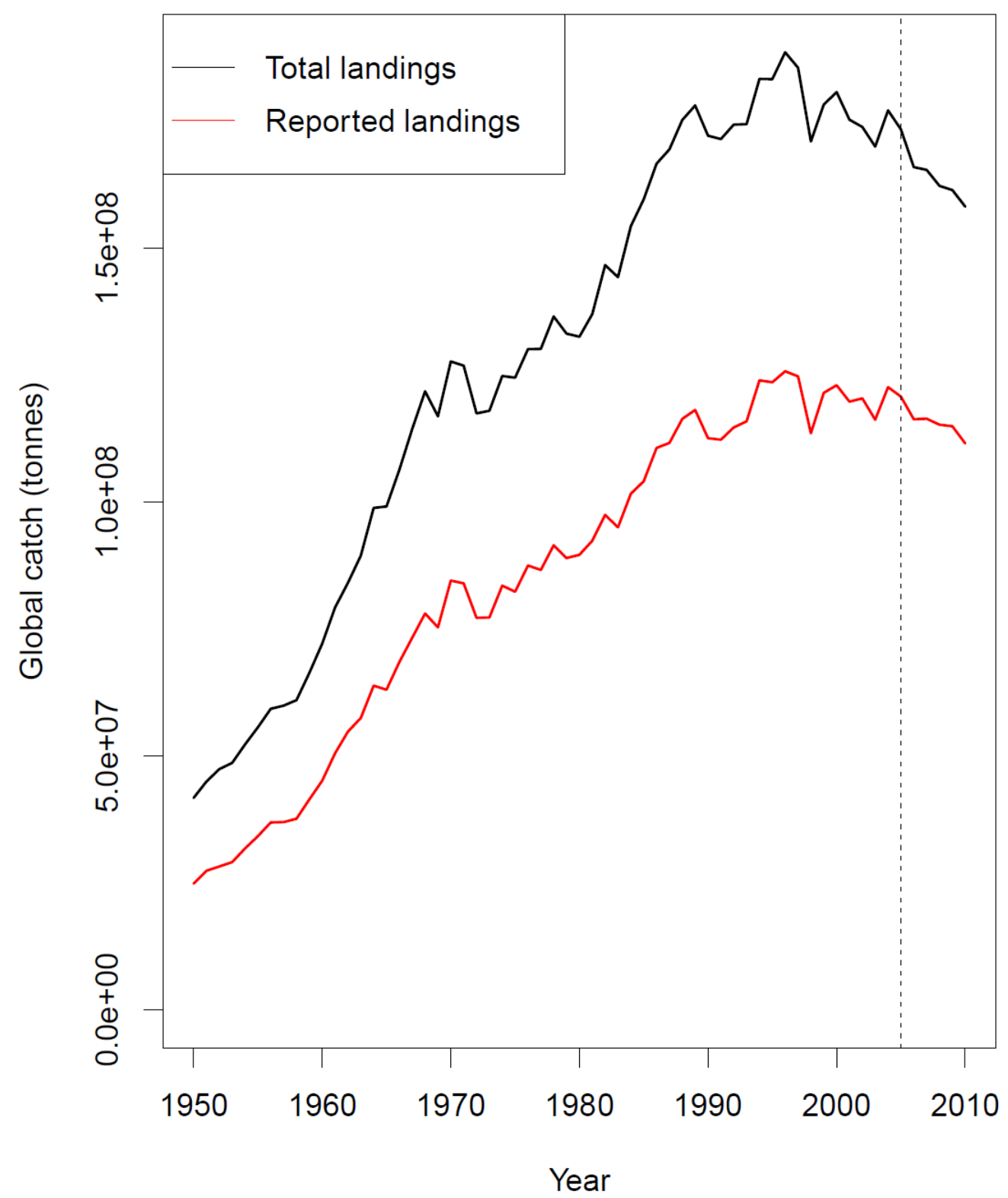

Figure S3: Variation in global catch trends in differing data sources. Figure shows trend in global catches as reported by the FAO (red line; FAO 2012) and estimated by the Sea Around Us Project (SAUP) (black line; Pauly \& Zeller 2015); the SAUP reconstruction includes catches due to illegal, unregulated, and unreported fisheries. The vertical dashed line indicates 2005, at which time the Fish-MIP protocol prescribes switching to a constant value for fisheries input data, in line with the ESM model switch from historical to future scenarios. For details on how fishing impacts are incorporated within the Fish-MIP models, see the main manuscript. 
BOATS IPSL tcb 1990-1999

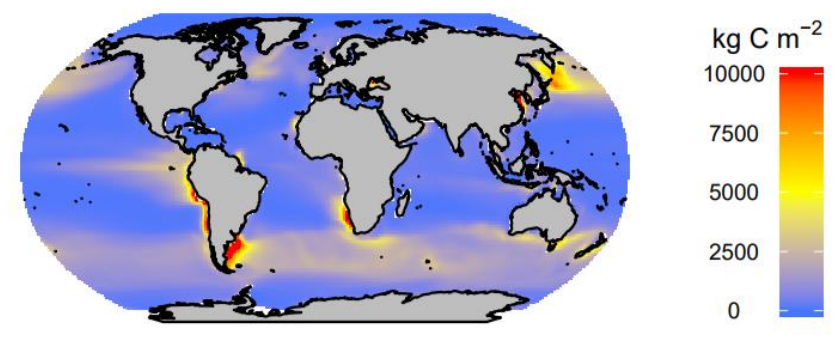

ECOOCEAN IPSL tcb 1990-1999
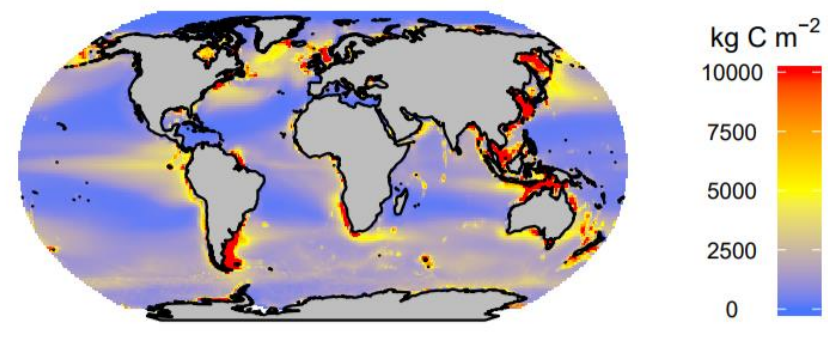

MACROECOLOGICAL IPSL tcb 1990-1999
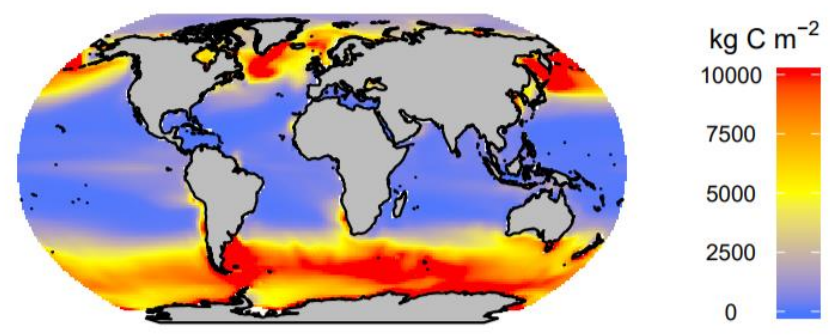

Model average tcb 1990-1999
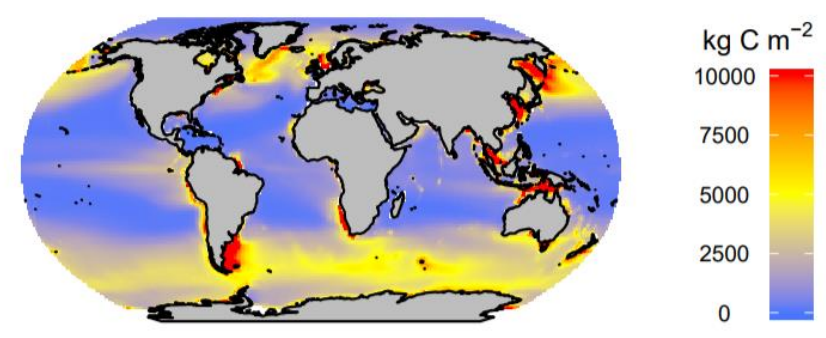

Figure S4: An example of Fish-MIP spatial model output. Figure depicts outputs from three of the global Fish-MIP models (BOATS, ECOOCEAN and MACROECOLOGICAL) and a modelaveraged value. The output variable is mean annual total consumer biomass $(t c b)$ under the IPSL-CM5A-LR unfished historical scenario for the period 1990-1999. 


\section{Supplementary references:}

FAO (2012). FishStat (Database), URI: http://ref.data.fao.org/database?entryId=babf3346-ff2d4e6c-9a40-ef6a50fcd422. Food and Agriculture Organization of the United Nations. Rome, Italy.

Pauly D and Zeller D (Editors) (2015). Sea Around Us Concepts, Design and Data (www.seaaroundus.org) 


\begin{tabular}{|c|c|c|c|c|}
\hline \multicolumn{5}{|c|}{ Optional output from global and regional models } \\
\hline $\begin{array}{l}\text { Biomass density of } \\
\text { commercial species }\end{array}$ & bcom & monthly & $\mathrm{g} \mathrm{C} \mathrm{m}^{-2}$ & $\begin{array}{l}\text { Discarded species not included (Fish and } \\
\text { invertebrates) }\end{array}$ \\
\hline $\begin{array}{l}\text { Biomass density (by } \\
\text { functional group / size } \\
\text { class) }\end{array}$ & $\begin{array}{l}b-<\text { class }>- \\
<\text { group }>\end{array}$ & monthly & $\mathrm{g} \mathrm{C} \mathrm{m}^{-2}$ & $\begin{array}{l}\text { Provide name of each size class }(<\text { class }>\text { ) and } \\
\text { functional group }(<\text { group }>\text { ) used, and provide a } \\
\text { definition of each class/group }\end{array}$ \\
\hline $\begin{array}{l}\text { Catch (by functional group / } \\
\text { size class) }\end{array}$ & $\begin{array}{l}c-<\text { class }>- \\
<\text { group }>\end{array}$ & monthly & $\begin{array}{l}\text { g wet biomass } \\
\mathrm{m}^{-2}\end{array}$ & $\begin{array}{l}\text { Provide name of each size class }(<\text { class }>\text { ) and } \\
\text { functional group }(<\text { group }>\text { ) used, and provide a } \\
\text { definition of each class/group }\end{array}$ \\
\hline
\end{tabular}

Table S1: Optional output from global and regional models. 


\section{File preparation instructions}

*These instructions have been modified from the original ISI-MIP instructions, found at:

https://www.isimip.org/protocol/isimip2b-files/

Default format is compressed NetCDF4. Some example shell scripts for output file preparation, example files, and instructions that help prepare output files in the correct format are provided on the ISI-MIP web page. They might need further adaption to individual use cases.

File naming should be as follows:

- all lower case letters

- file specifiers (tags) separated with "_" delimiter

- dash between specifiers (no further underscore within specifiers)

- fixed order of specifier type:

○ model [apecosm|ecoocean|ewe|...]

○ driving GCM/Reanalysis model [cesm1-bgc|ipsl-cm5a-lr|gfdl-esm2m|gfdlreanalysis]

○ climate scenario [hist|rcp2p6|rcp4p5|rcp6p0|rcp8p5]

$\circ$ with/without diazotrophs [w-diaz|wo-diaz]

- Fishing scenario [fishing|no-fishing]

○ ocean acidification scenario [oa|no-oa|

○ variable name $[\mathrm{tc}|\mathrm{tsb}| \mathrm{b} 10 \mathrm{~cm}|\mathrm{~b} 30 \mathrm{~cm}| . .$.

$\circ$ region [global|baltic-sea|cook-strait...]

$\circ$ temporal resolution [daily|monthly|annual]

- first year of reporting period

- last year of reporting period

$\circ \quad[. n c 4 \mid . c s v]$

- don't omit your default values of specifiers, always give a value

- split ESMs into historical and scenario periods. transition in 2005 -> 2006

Examples:

- ewe_gfdl-reanalysis_hist_wo-diaz_fishing_no-ao_b10cm_northsea_monthly_1991_2005.nc4

- macroecological_ipsl-cm5a-lr_rcp2p6_wo-diaz_no-fishing_nooa_tcb_global_annual_2006_2044.nc4 